\title{
IS THE PATTERN OF NEUROLOGICAL DAMAGE OF DIAGNOSTIC VALUE IN THE RADIOLOGICAL ASSESSMENT OF ACUTE CERVICAL SPINE INJURY?
}

\author{
By A. T. Scher, M.B., Ch.B., D.M.R.D. \\ Department of Radiology and Spinal Cord Injuries Centre, \\ Conradie Hospital, Cape Town, South Africa
}

Key words: Acute cervical spine injury; Radiological studies; Pattern of neurological deficit.

\section{Introduction}

RADIOLOGICAL demonstration of the site and type of injury in patients who have sustained acute cervical spinal cord damage is important both as regards to treatment and as an indication of the mechanism of injury. Unfortunately, in some cases no radiological evidence of injury is seen on the initial radiographs. The problem of failure to demonstrate orthopaedic injuries in patients who have suffered trauma of a magnitude sufficient to cause spinal cord damage is one of considerable interest, and has been previously investigated by us, Scher (1976).

In 1974 Marar reported that a correlation exists between radiological patterns of skeletal injury and clinical patterns of neurological deficit. In common with other workers (Sutton, I973 \& Bedbrook, I973), we have not noted any close correlation between the orthopaedic injuries and the type of neurological deficit in patients with acute traumatic tetraplegia. Of particular interest was the corollary evident in Marar's observations, that if a specific pattern of neurological deficit is present on clinical examination and the corresponding skeletal injury is not radiologically evident, then further radiographic investigations should be instituted to demonstrate the expected injury.

An analysis of a series of cases has therefore been made to assess whether the correlations noted by Marar are applicable to our patients.

\section{Materials and Methods}

The orthopaedic injuries, as reflected on the initial radiographs and the neurological status recorded on admission, were analysed in I49 patients with acute injury to the cervical spinal cord. These patients were admitted to the Spinal Cord Injuries Unit at our hospital during the three-year period I975 to I978. Patients with fractures of the upper cervical spine ( $\mathrm{CI}_{\mathrm{I}}$ and $\mathrm{C}_{2}$ ) were excluded, as were patients injured as a result of stab or gunshot wounds. The majority of patients analysed sustained injury as a result of motor accidents, industrial accidents, sports accidents or assaults.

\section{Results}

The findings in our series of patients were analysed in a similar manner to that of Marar (as shown in Table I), who divided his patients into five groups according to the clinical pattern of neurological damage. 
Group I. In this group there was total motor and sensory loss to all four limbs from a definite localised level, i.e. total transection of the spinal cord. This group of 84 cases is the largest in our series. Marar found that transection of the spinal cord only occurred in association with two orthopaedic injuries, bilateral locked facets (dislocation), and burst (compression) fractures of the vertebral bodies. In our series transection of the spinal cord was found not only in association with the above injuries but also with unilateral facet dislocation, anterior cervical subluxation and hyperextension injury, manifesting either with fractures of the spinous processes and neural arches, or without radiographic evidence of injury. Bilateral facet dislocation was the most common cause of this injury, as was observed by Marar. The second commonest cause was unilateral facet dislocation, followed by burst fractures.

Group 2. In this group a clinical pattern of motor loss of a variable degree, either in the upper extremities only or in all four limbs associated with patchy sensory loss, was present. This conforms with the syndrome of 'central cord injury' described by Schneider et al. (1958). In Marar's series this pattern was found only in association with hyperextension injuries and unilateral facet dislocation. In our series this pattern was also found with burst fractures and subluxations. See Table I.

Group 3. The clinical pattern of this group was one of complete paralysis of all four limbs associated with hypoalgesia to the level of the lesion with preservation of motion, position and vibration sense. This is the 'anterior spinal cord syndrome' described by Schneider (1955). Marar found this pattern associated with burst fractures which was similar to the findings in the small group of four cases in our series.

Group 4. The clinical pattern of this group was one of partial motor weakness without sensory loss and which Marar found in association with unilateral facet dislocation and fractures of the axis. In our series this pattern was also found with hyperextension injuries, burst fractures and anterior subluxations as shown in Table I.

Group 5. In this group the clinical pattern was that of the Brown-Séquard syndrome. Marar observed this pattern in association with unilateral facet dislocation, a similar finding in the two patients of our series.

\section{TABLE I}

Radiological appearances and neurological deficit in I49 patients with acute cervical spinal cord injuries

\begin{tabular}{|c|c|c|c|c|c|c|c|}
\hline & $\begin{array}{l}\text { Bilateral } \\
\text { locked } \\
\text { facets }\end{array}$ & $\begin{array}{l}\text { Unilateral } \\
\text { locked } \\
\text { facets }\end{array}$ & $\begin{array}{l}\text { Without } \\
\text { radiographic } \\
\text { evidence of } \\
\text { injury }\end{array}$ & $\begin{array}{c}\text { Compression } \\
\text { (burst) } \\
\text { fractures }\end{array}$ & Subluxations & $\begin{array}{l}\text { Fractures } \\
\text { of spinous } \\
\text { processes and } \\
\text { neural arches }\end{array}$ & Total \\
\hline Group I & 37 & I9 & 5 & I6 & 3 & 4 & 84 \\
\hline Group 2 & - & 9 & 12 & 6 & 6 & 6 & 39 \\
\hline Group 3 & - & - & - & 2 & - & 2 & 4 \\
\hline Group 4 & - & 4 & 2 & IO & I & 2 & I8 \\
\hline Group 5 & 一 & - & - & 2 & 一 & 2 & 4 \\
\hline Total & & & & & & & I49 \\
\hline
\end{tabular}




\section{Discussion}

There is poor correlation between the findings in our series and those of Marar. Only in the two smallest groups ( $3 \& 5)$ was a similarity noted. A previous analysis performed in our Unit, Shrosbree (I977), on a large group of patients who presented with acute central cord syndrome, demonstrated that this was associated with a greater variety of skeletal injuries than was observed by Marar in Group 2.

When considering the discrepancy between our findings and those of Marar two points are noteworthy. The first is that the designation of various cord syndromes (central cord, anterior cord, etc.) are anatomical indications of pathological lesions of the spinal cord which may be asymmetrical and do not necessarily conform to a specific set of characteristics (Hardy, 1977). Therefore an exact clinical distinction between the various cord syndromes cannot always be made. This may make it difficult to correlate the neurological deficit present after spinal cord injury with the radiological appearances.

The second point is that the radiological appearances on the initial radiograph may not accurately reflect the true extent of displacement sustained at the moment of injury. This situation is demonstrated in Case No. I presented by Marar, which describes a patient with complete cord transection due to bilateral apophyseal joint dislocation which had spontaneously reduced and therefore showed no abnormality on the initial radiograph.

In spite of the poor correlation between neurological deficit and skeletal injury observed in our series we are reluctant to perform radiographic procedures, such as tomography or stress views, on patients with acute spinal cord injury. These examinations inevitably require manipulation of the head and neck which is undesirable. Bedbrook (1973) has commented that 'early in the pathological process the cord swells rapidly and probably fills the neural canal over quite a distance of the cord. Great gentleness is required at the time of initial management to ensure that no further damage is sustained to a cord which is already swollen, and therefore without its usual elacticity and movement pattern'.

We are aware that conventional radiography of the cervical spine is essentially a crude method of excluding the presence of fractures. Tomography, preferably thin section multidirectional, is a superior method of fracture visualisation and will demonstrate fractures in many patients who present with spinal cord damage, but without evidence of injury on the plain radiographs. Using this technique, Maravilla et al. (1978) noted that in patients with acute cervical trauma that only 4I per cent of cervical fractures were evident on plain radiography, while a further 59 per cent were demonstrated by tomography.

Although tomographic demonstration of small fractures is of considerable interest, it is questionable whether the findings are of practical clinical value in the treatment of patients with acute cervical spinal cord injury, and whether they justify moving the patients for tomography and subjecting them to increased irradiation. In our Unit such patients are treated with skull traction by Crutchfield tongs and immobilised for twelve weeks. Those patients without radiographic evidence of injury (usually due to hyperextension force), are treated in a similar manner. Therefore the visualisation of small fractures of the laminae, pedicles and lateral masses will not influence our conservative regimen of treatment.

Irrespective of the type and degree of cord damage present after cervical spine injury, adequate demonstration of the lower cervical spine, particularly $\mathrm{C}_{7}$ and $\mathrm{TI}_{\mathrm{I}}$, is essential on the lateral radiograph. This is a basic principle of the utmost importance, and inadequate demonstration of this area is the most common cause 
of failure to diagnose fractures and dislocations of the cervical spine. Technical difficulties in the radiography of the lower cervical spine may arise when the patient is in the supine position but, as we have shown previously (Scher, 1977), tomography is not necessary for visualisation of this area, which can be demonstrated by using conventional equipment and without manipulation of the head or neck.

The question of when mobility studies (flexion-extension) should be taken is a controversial one. We prefer to wait until the danger of inducing or aggravating neurological deficit is no longer present and to perform this examination three weeks after injury. Muscular spasm and associated pain, often present after injury, prevent adequate movement and radiographs obtained under these conditions are of little value.

\section{Conclusion}

This analysis has revealed poor correlation between skeletal injury, as demonstrated radiologically, and the type of spinal cord damage. The findings in the three major groups (I, $2 \& 4$ ) are at variance with thcse of Marar (I974). In all three groups a greater variety of skeletal injuries were found in association with the different patterns of neurological deficit in our series as compared to the specific injuries recorded by Marar.

Because of the above findings we believe that there is no indication for aggressive radiological investigations to identify a specific injury in relation to a specific pattern of neurological deficit in the patient with acute spinal cord injury. Provided that the entire cervical spine, including $\mathrm{C}_{7}$ and $\mathrm{T}_{\mathrm{I}}$, is adequately visualised on the lateral projection, further procedures such as tomography and mobility studies should be deferred until a later stage. These examinations are unlikely to produce any results which would significantly alter the management of a patient with clinically established neurological deficit due to acute cervical spinal cord damage.

\section{SUMMARY}

Correlation between the pattern of neurological deficit present and the radiographic appearances of the cervical spine after acute cervical spinal cord injury has been suggested. An analysis of I 49 cervical spinal cord injury patients has been made to assess this observation. The analysis has shown poor correlation between the initial radiographs and the pattern of spinal cord injury. Because of this, and the undesirable movement of such patients, it is concluded that additional radiographic procedures, mobility studies or tomography, should not be undertaken to exclude possible injuries which have not been demonstrated on routine cervical spine views.

\section{RÉSUMÉ}

On pense qu'il existe une certaine corrélation entre le schéma du déficit neurologique et le tracé radiographique de la colonne vertébrale à la suite d'un accident sérieuse du cordon cervical. Une étude de I 49 patients accidentés du cordon cervical confirme cette hypothése. Cette étude a montré une faible corrélation entre les premiéres radiographies et le schéma d'un accident de la colonne vertébrale. Pour cette raison et aussi a cause de l'immobilité de tels malades, on en conclut que des procédés radiographiques supplémentaires, études de mobilité ou tomographie sont déconseillés pour éviter tout accident possible, qui n'aurait pas été montré sur un cliché normal de la colonne vertébrale.

\section{ZUSAMMENFASSUNG}

Man vermutet einen Vergleich zwischen Art des neurologischen Deficit und der radiologischen Erscheinung der Halswirbelsäule nach akuter Halswirbelsäulenverletzung. 
Eine Analyse von I49 Patienten mit Halswirbelsäulenverletzung ist gemacht um diese Beobachtung zu untersuchen. Die Analyse hat beweisen daß da ein schwacher Vergleich ist zwischen den ersten Röntgenaufnahmen und die Art der Wirbelsäulenverletzung. Wegen dieser Eracheinung und wegen der unerwünschten Bewegung dieser Patienten, Kam man zum Entschlusz daß weitere Röntgenverfahren, Beweglichkeitsstudien oder Tomographie, nicht gemacht werden sollen um mögliche Verletzung der Wirbelsäule, welche nicht bei einer Röntdenaufnahme der Halswirbelsäule, welche nicht bei einer Röntdenaufnahme der Halswirbelsäule zu sehen war, zu verhindern.

\section{REFERENCES}

BEDRooK, G. M. (1973). Proceedings of the nineteenth veterans administration spinal cord injury conference, Washington, D.C., pp. 8-I 5. U.S. Government Printing Office.

HARDY, A. G. (I977). Report on discussion of papers at Annual Scientific Meeting of the International Medical Society of Paraplegia. Paraplegia, 14, 258.

Maravilla, K. R., Cooper, P. R. \& Sklar, F. H. (I978). The influence of thin-section tomography on the treatment of cervical spine injuries. Radiology, 127, I3I.

MARAR, B. C. (I974). The pattern of neurological damage as an aid to the diagnosis of the mechanism in cervical spine injuries. F. Bone ft. Surg., 56-A, I648.

SCHER, A. T. (I976). Cervical spinal cord injury without evidence of fracture or dislocation -an assessment of the radiological features. S. Afr. med. F., 50, 962.

SCHER, A. T. \& VAMBECK, V. (1977). An approach to the radiological examination of the cervico-dorsal junction following injury. Clin. Radiol., 28, 243.

Schneider, R. C., Thompson, M. J. \& Rebin, J. (I958). The syndrome of acute central cervical spinal cord injury. F. Neurology, Neurosurgery and Psychiatry, 21, 261.

SCHNEIDER, R. C. (1955). The syndrome of acute anterior spinal cord injury. F. Neurosurgery, 12, 95 .

SHROSBREE, R. D. (1977). Acute central cervical spinal cord syndrome-aetiology, age, incidence and relationship to the orthopaedic injury. Paraplegia, 14, $25 \mathrm{I}$.

Sutton, N. G. (1973). Injuries of Spinal Cord, p. 74. Butterworth \& Co. 